"I can announce to naturalists that this is the true Promised Land. Here nature created a special sanctuary where she seems to have withdrawn to experiment with designs different from those used anywhere else. At every step one finds more remarkable and marvellous forms of life."

Ridley describes how Baret discovered Bougainvillea in the forests of Rio de Janeiro using the doctrine of signatures, a medieval method by which herbalists attributed curative powers to plants on the basis of their appearance - a walnut was good for brain trouble, red things for wounds. Commerson had an ulcerating sore on his leg, so Ridley writes of Baret searching frantically for a cure, only to find it in the red bracts of Bougainvillea holding a pea-like pod that reminded her of the red-flowered runner beans from home. However, Bougainvillea does not have fruits like a pea, nor do the notes on the specimen mention any medicinal value.

In his notes, Commerson honoured high-ranking members of the expedition - its leader is commemorated in Bougainvillea, Nassau-Siegen in Nassauvia - but he did not publish these names. Bougainvillea was formally described in 1789 by Antoine Laurent de Jussieu, a French botanist who used Commerson's specimens and notes. Commerson also proposed the name Baretia for a Malagasy tree.

Ridley maintains that Commerson was an arrogant man who named things for himself. Yet the International Plant Names Index shows 119 species of flowering plants named in his honour - by others. None is noted as 'commersonii' on its original label. Commerson's Baretia was never published, not because someone wanted to do Baret down, but because it was found, on the specimen's return to Paris, that the genus already had a name.

After Commerson died, Baret married a French officer, Jean Duberna, on Mauritius and returned to France in 1774. She was awarded a state pension from 1785 in recognition of her bravery and contributions. She was not forgotten, although she never practised botany again.

Science was as collaborative then as it is now, but women's contributions were often overlooked in favour of those of male colleagues - a trend that continues today. Baret and other neglected contributors deserve recognition, but she does not need to be cast as a victim to be seen as a success, or her undoubted accomplishments overinflated. She, and women scientists in general, deserve better.

Sandra Knapp is a botanist at the Natural History Museum, London SW7 5BD, UK.

e-mail:s.knapp@nhm.ac.uk

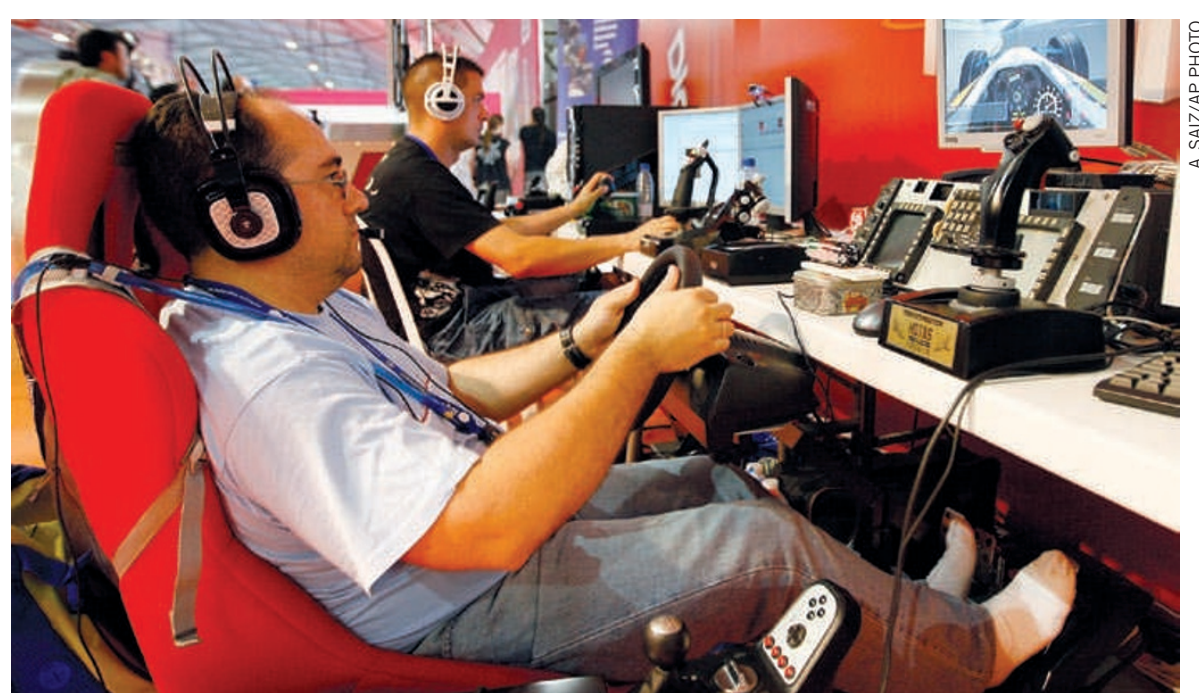

The mind's ability to adapt suggests that it can cope with our wired world — for better or worse.

NEUROSCIENCE

\title{
Browsing and the brain
}

\section{Two books reach opposite verdicts on how the Internet affects us, find Daphne Bavelier and C. Shawn Green.}

$\mathrm{W}$ henever a new technology reaches a tipping point of popularity, questions soon follow about its effects on society. The rise of the Internet has provoked two books probing its impact on the human brain. The fact that the authors reach opposite conclusions, despite relying on the same scientific evidence, underscores how little research has been done on this topic.

Nicholas Carr's The Shallows laments the possibility that long-term Internet exposure will sap us of our capacity for contemplation. At the base of his argument is the fact that the human brain is remarkably plastic. Carr makes this point compellingly using a mixture of historical anecdotes and interviews with experts in the neuroplasticity field, such as Michael Merzenich and Eric Kandel.

Having established that brains are constantly reshaped by experience, Carr argues that changes induced by Internet use, such as greater brain activation during web browsing, may not be in our best interests. If the brain adapts completely to the frenetic nature of the Internet, he warns, we may lose our capacity for absorbing practices such as reading a book. He worries that we may lose the very essence of what makes us human.

Nick Bilton's I Live in the Future is much more optimistic. Humming with enthusiasm for the continuing Internet revolution, he argues that social and cognitive changes are an inevitable consequence of any major technological advance and that our new abilities cannot be put back in the box.
The Shallows: What the Internet is Doing to Our Brains/How the Internet is Changing the Way We Think, Read and Remember

NICHOLAS CARR

W. W. Norton/Atlantic Books: 2010. 276 pp./384 pp. $\$ 26.95 / £ 17.99$

I Live in the Future \& Here's How it Works: Why Your World, Work, and Brain are Being Creatively Disrupted

NICK BILTON

Crown: 2010. 304 pp. $\$ 25, £ 16.99$

Such tension is to be expected whenever new forces enter society. By analogy, Carr discusses historical fears that the written word would act as a replacement for memory, resulting in humans that were 'shallower thinkers. Bilton notes early worries that the freedom of travel offered by the railway would result in weakening moral standards. Both books review suspicions that most people would prefer to listen to a book than to read one, leading to concerns that the invention of the phonograph would kill the art of writing.

Is the Internet different? Bilton and Carr rely on the same scientific facts to argue persuasively for opposite positions. For example, functional magnetic resonance imaging studies show that Internet searches activate a larger network of brain areas than does simple text reading. Web browsing also requires additional types of mental processing evaluating hyperlinks to make navigational decisions and filtering photos, videos and menus. As a result, brain activation is greater during Internet searches in people who are 
'net savvy' than in those who are 'net naive.'

These findings cannot answer the question of whether such changes are good or bad. Conclusions are coloured by the authors' values. Bilton treats the adaption of the 'net savvy' as positive: "the brains were learning, benefiting from practice and experience". Carr comes to the opposite conclusion: "When it comes to the firing of our neurons, it's a mistake to assume that more is better."

Part of the problem is the paucity of scientific studies on the effects of modern technologies on the brain. It is a testament to both authors' skills that they were able to produce entire books on works so sparse. Unfortunately, to fill the pages, they lump information into categories that are too diverse to be useful. For example, both treat the use of all Internet technology - web browsing, web searching, texting, tweeting, video games and so on - as a single activity, despite the fact that such variety is unlikely to have one distinct effect. As with food, the effects of technology will depend on what type of technology is consumed, how much and for how long.

History suggests that technology does not change the brain's fundamental abilities. The general principles of brain organization have not changed for thousands of years - probably since the rise of language. Major technological advances do not create de novo brain structures. They do, however, take advantage of the cognitive flexibility of the human mind.

With each new technological development, we see a shift in the cognitive abilities and brain functions that society values most. The advent of writing systems, so celebrated by Carr, devalued the role of oral memorization through storytelling as cherished by the Greeks. Great orators such as Socrates would have lamented that Carr has lost the memory skills necessary for passing on knowledge through stories to future generations. Yet he has gained other skills by entraining alternate brain networks for reading and text analysis.

Just as it was difficult to say at the time whether the advent of writing was good or bad, a value judgement of the effect of the Internet is impossible. But it is a tribute to neural plasticity that, with each new technological development, our brains adapt — for better or for worse.

Daphne Bavelier is a professor in the Department of Brain and Cognitive Science at the University of Rochester, New York 14627, USA.

e-mail:daphne@cvs.rochester.edu C. Shawn Green is a cognitive scientist in the Department of Psychology at the University of Minnesota, Minneapolis, Minnesota 55455, USA.

\section{Abstract relativity}

\section{A Paris exhibition contrasts 1920s depictions of the fourth dimension, find Stefan Michalowski and Georgia Smith.}

$\mathrm{T}$ The birth of modern physics a century ago fired artistic as well as scientific imaginations. This can be seen in the Pompidou Centre's current exhibition of abstract art, covering Dutch painter Piet Mondrian and the De Stijl group, led by another Dutchman, Theo van Doesburg.

A series of canvasses illustrates the evolution of abstract techniques, from the soft contours of impressionism to the spare geometry of cubism. "We arrive at a portrayal of other things, such as the laws governing matter," Mondrian wrote. Cubist techniques were inspired, in part, by the multi-dimensional mathematics of Henri Poincaré and his contemporaries.

Most of the exhibition is rightly devoted to Mondrian and the development of his recognizable mature style. From a minimal toolbox of visual elements - white canvas, black lines and simple blocks of red, yellow or blue - emerge geometric compositions of startling intensity and elegance.

Mondrian was deeply influenced by theosophy, a spiritual movement grounded in ancient texts that was bent on uncovering universal truths in art, religion and science. $\mathrm{He}$ penned reams of theory as to why his abstract style was the appropriate expression of these "great generalities" for modern times.

A quiet introvert from a Calvinist family, Mondrian became a mentor to van Doesburg, by contrast a flamboyant young painter who had three wives and many artistic cliques in his short life (he died aged 47). When van Doesburg moved to Paris in 1923, the two men worked closely: their canvasses form a dialogue as each sparked fresh innovations from the other. But their intense relationship exploded a year later - and one of the flashpoints was the theory of relativity.

The public learned about Albert Einstein's discoveries after the First World War, when the solar eclipse of 1919 confirmed general relativity by showing that gravity can bend light. In Paris, space-time became a catchword in avantgarde circles. Artists from futurists to Dadaists latched on to the new ideas. Van Doesburg had already flirted with spatial geometry in
Mondrian/De Stijl four dimensions: the Centre Pompidou,

Paris.

Until 21 March 2011. exhibition includes some of his tesseracts, projections on paper of four-dimensional cubes. Then, in the 1920s, he began trying to evoke time and change - four-dimensional space-time - in his paintings.

Mondrian rejected van Doesburg's attempt, and the two split over it. Symbolic of their rift was van Doesburg's use of dynamic diagonal lines, which contrasted with Mondrian's strict vertical and horizontal grids. But the quarrel went deeper than diagonals: Mondrian's doggedly developed style had become too much of a constraint for his former coterie.

The De Stijl artists wanted to remake the human environment by designing furniture, buildings and cities based on their primarycoloured, idealized structures. Van Doesburg experimented with architectural designs and films incorporating the fourth dimension. Some of these products are displayed in the exhibition, but the role of the fourth dimension is not clearly shown or explained. The artists themselves do not always seem to have grasped the difference between a fourth dimension in space versus one in time.

As the artists tried to incorporate the newfound laws of physics in their expressions of absolute truth about the Universe, history ambushed them. Their comrades in abstraction were soon brutally dismissed by the Soviet and Nazi authorities. Einstein helped to pull the rug out from under their depictions of the 'absolute' by dissolving special relativity's neat geometries into quantum theory's fuzzy clouds of probability. But Mondrian's precise vision, with its subsumed scientific borrowings, continues to intrigue and delight.

Stefan Michalowski is a former particle physicist and executive secretary of the OECD Global Science Forum in Paris. Georgia Smith is a journalist based in Paris. e-mails: stefanm@noos.fr; georgias@noos.fr

This article does not represent the views of the OECD. 